\title{
A Study To Assess The Effect Of Information Education Communication Package On Knowledge Regarding Estrogen Dominance In Precocious Puberty Among Mothers Of School Going Girls In Selected Urban School At Puducherry.
}

${ }^{*}$ Renuka.K\& **Vijayaraj.R,

\begin{abstract}
:
Objectives: to assess the knowledge of the mothers regarding estrogen dominance \& to determine the effectiveness of information education communication package on knowledge of precocious puberty. Method: Pre experimental with One Group pre- test- post- test- Design. Result: There was a highly significant difference between mean post-test and pre- test knowledge scores $(p<0.000)$. Conclusion: Hence the health education programme was an effective teaching strategy for improving the knowledge.
\end{abstract}

Keywords: Information Education Communication, Estrogen Dominance, Precocious

Puberty

\section{Introduction}

Estrogen dominance is a hormonal state that occurs when amount of estrogen in the body increases while the level of progesterone stays the same or decreases. Progesterone, another hormone is the body's natural counterbalance to estrogen. The imbalance between the two chemicals can be caused by abnormal body function, exposure to chemicals containing estrogen, or the use of medications that stimulate or suppress hormone production. Estrogen is typically considered the female hormone due to the fact it is responsible for many definitive feminine traits, like breasts, menstruation, and lactation. Yet estrogen is naturally found in both sexes, just significantly less in men. ${ }^{3}$ Mothers play an essential role in maintaining a normal reproductive growth in a children. So the researcher has planned to conduct an Information Education Communication Programme among mothers in preventing precocious puberty. ${ }^{1}$

\section{Objectives}

1. To assess the knowledge of the mothers regarding estrogen dominance in precocious puberty.

2. To determine the effectiveness of Information Education Communication package on knowledge of precocious puberty.

3. To find out the association between knowledge of mothers and their selected demographic variables.

\section{Hypotheses}

H1-Knowledge level of mothers differ

before and after Information 
- Education Communication package on estrogen dominance in precocious puberty.

- H2-There is association between knowledge of mothers and their selected demographic variables

\section{Methodology:}

Pre experimental with One Group pre- testpost- test- Design. The study was conducted in Government primary school(urban) uppalam,puducherry. The sample was collected using convenience sampling method. It consisted of 30 mothers of school going girls studying in $3^{\text {rd }}, 4^{\text {th }}$ standard. The result were computed by using descriptive and inferential statistics.

\section{Result:}

Assessment of level of knowledge of mothers regarding Precocious Puberty in Pre test

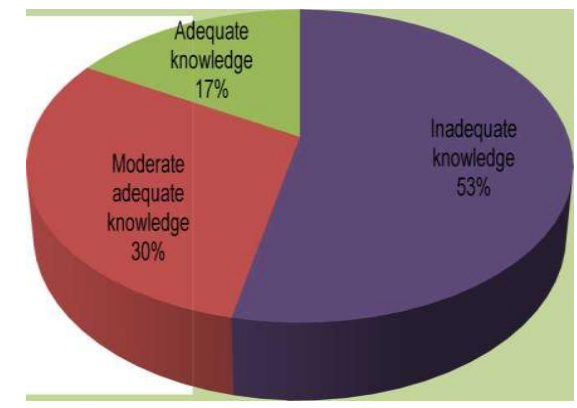

Assessment of level of knowledge of mothers regarding Precocious Puberty in Post test

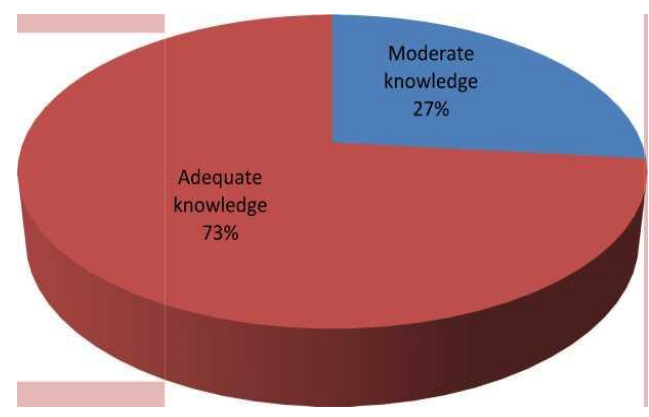

Effectiveness of Information Education

\section{Communication package on knowledge of precocious puberty}

\begin{tabular}{|l|c|c|c|c|}
\hline Knowledge & Mean & SD & 't' test & $p$-value \\
\hline Pre-test & 8.73 & 4.69 & \multirow{2}{*}{-11.58} & $\begin{array}{c}\mathrm{P}=0.000^{*} \\
\mathrm{~S}\end{array}$ \\
\hline Post-test & 15.47 & 3.04 & & \\
\hline
\end{tabular}

The above table showed that, the mean knowledge scores of the mothers of school going girls obtained after the health education programme was higher than those obtained in pre-test. There was a highly significant difference between mean post-test and pre- test knowledge scores $(\mathrm{p}<0.000)$. Hence the health education programme was an effective teaching strategy for improve knowledge.

\section{Implication \&Recommendation}

- A similar study can be conducted with a large sample among urban school.

- Study can be done to assess the intake of food which increases estrogen level and leads to precocious puberty.

- An Experimental Study can be conducted on evaluating the Estrogen Level of Children with Puberty status.

\section{Conclusion}

The present study indicated that the knowledge of mothers has improved and they obtained adequate level of knowledge as well as decreased their girl's children practice of consuming junk food. So the continuous awareness in the schools and community area are necessary to change the knowledge of the mother. Hence, Health care professional should also start awareness campaign to increase awareness of precocious puberty among the mothers of school going girls below age group of 8 
years and it should be conducted in both rural and urban area among mothers.

\section{References:}

1. Szwarc Sandy, Junk food science weekend special: fears about early puberty in girls. 10 March, 2007. http: // junk food science. blogspot. com /2007/03

2. High meat diet may lead to early puberty for girls. Av from URC: http://www.brostol.ac.uk/news/ 2010/706/html.

3. Dr. John R lee, MD and Wrginia Hopkins, "book on natural progesterone", warner book. 2004,page no: 437

4. Book: Mayo Clinic Famliy Health Book, 4thEdition, $2^{\text {nd }}$ Jan, 2014. www. Mayoclinic.Org/../200297
5. Mongensen SS, etal. Pathalogical and incidental findings on Brain MRI in a single-center study of 229 consecutive girls with early or Precocious puberty. $12^{\text {th }}$ Jan, 2012. www. uptodate.com.

6. Prithvijit Mitra, TNN, city girls Reach Puberty earlier: study, $7^{\text {th }}$

Sep 2006,0300hrs IST the Times of India.

7. Deadroff, India parents favor children with Precocious puberty Hormone surge Injection. 29 $9^{\text {th }}$ sep, 2011. www. China-dail.org.

8. Dr. Paul, kaplowitz, child obesity triggers early puberty, $6^{\text {th }}$ May, 2012. www.teens.about.com. 9. U.S. Girls starting puberty early by Amanda Gardner,Health. Com. 10 $0^{\text {th }}$ August, 2010.

\section{DUMPING SYNDROME}

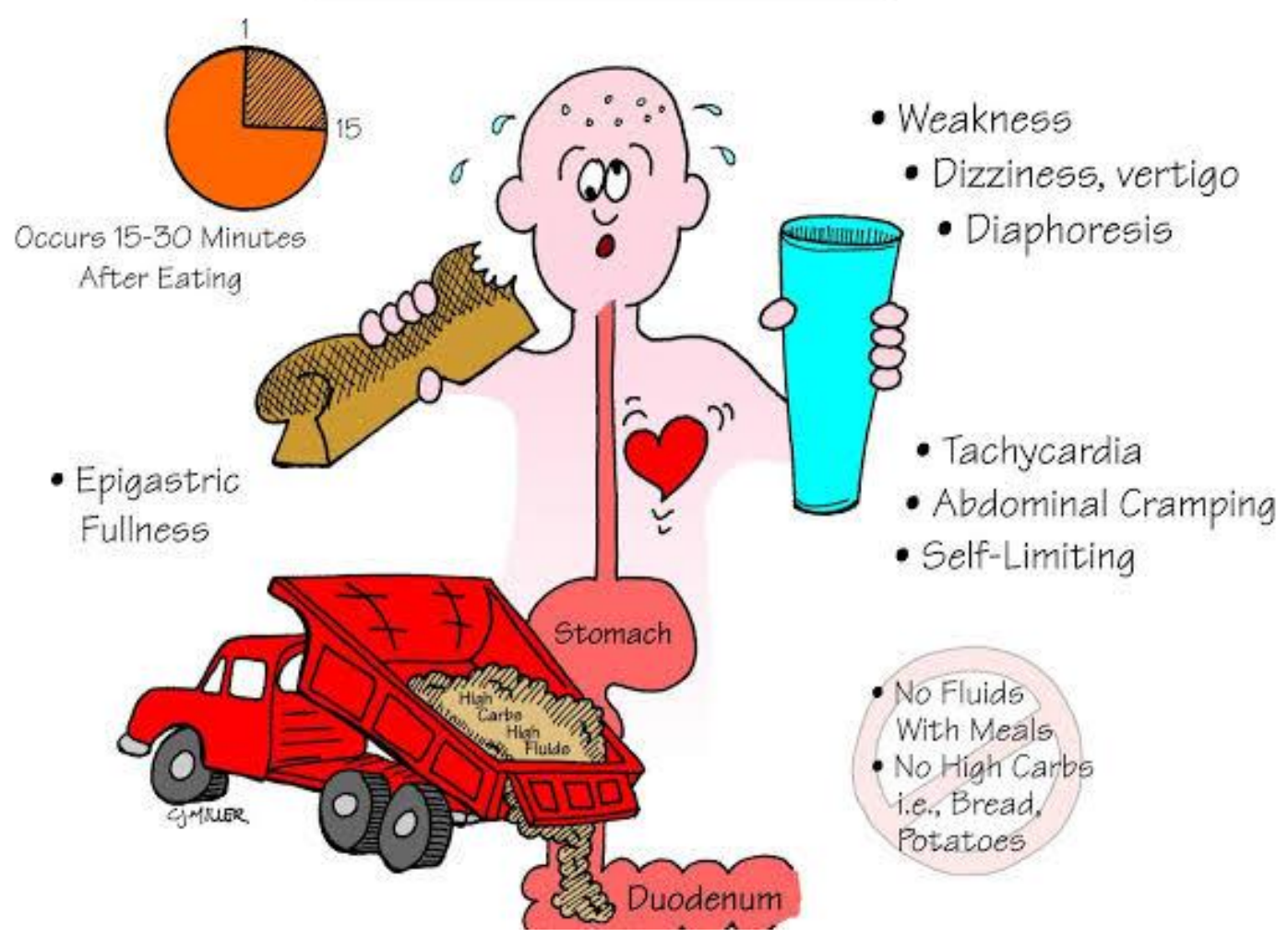

